\title{
Pandemics, climate change, and disability related to $\mathrm{SCI}$
}

\author{
Marcalee Alexander ${ }^{1,2}$
}

Received: 19 April 2020 / Revised: 21 April 2020 / Accepted: 21 April 2020

(c) International Spinal Cord Society 2020

Persons with disabilities, including persons with Spinal Cord injury (SCI), are susceptible to disasters. In this point-counterpoint series, the concerns of persons with SCIs to hurricanes and the unique issues of persons with SCIs in relationship to corona virus disease 2019 (COVID19) are described. Professionals and consumers must be educated about these concerns to optimize the health and safety of persons with SCIs. Moreover, these concerns may be similar in persons with other etiology of disability and professionals must use this time accordingly as a learning experience for future events. SCI is one of the most profound disabilities that an individual can experience. SCI not only results in organ system changes, but it also impacts the person's ability to perform activities of daily living and their mobility, which often results in dependence on equipment and the need for daily physical assistance from another individual. These concerns make persons with SCIs one of the most vulnerable groups in society to the impacts of disasters. In this timely point-counterpoint series we confront two of the major issues of our time: disasters related to the climate crisis [1] and the COVID-19 pandemic [2].

The climate crisis will increase the frequency of fires and extreme weather conditions such as droughts, excessive heat, storms, and floods, amongst other societal concerns. Shapiro et al. [1] provide information related to one of the most troublesome issues: the increasing threat of cyclones and hurricanes around the world. In this paper, the authors discuss ways to prepare for hurricanes, highlighting the concerns for persons living with SCI, their family members, and the professionals who care for them. The authors provide excellent tips that are worth review by all professionals, regardless of whether the area they live in is prone

Marcalee Alexander

spinalcordmd@live.com

Telerehabilitation International, Birmingham, AL, USA

2 University of Alabama at Birmingham School of Medicine, Birmingham, AL, USA to hurricanes or cyclones. Moreover, this paper addresses the educational needs of health care professionals working in SCI where in a recent survey [3] 56\% of respondents had acknowledged that climate change had already impacted their clients with SCIs and $85 \%$ were interested in further education.

COVID-19 has quickly enveloped our planet and created an unprecedented need for worldwide unity and collaboration $[4,5,6]$ such as the work done through the International Spinal Cord Society. In fact, we would be prudent to consider the COVID-19 pandemic as a drill for how our civilization needs to respond to the climate crisis with the recent worldwide immediate transition to telemedicine, on line education, and communication. Despite the profound crisis, the decrease in incessant travel and an abrupt decrease in pollution can be considered beneficial side effects. Moreover, in this current pandemic, a tremendous need for education of professionals and persons with lived experiences with SCI has been documented [6] in a similar fashion to the climate crisis. The first reported case of an individual with comorbid SCI and COVID-19 [7] from Italy documented the difficulties in caring for people with SCIs. The baseline comorbidities that people with SCI commonly have such as frequent urinary tract infections, respiratory disorders, propensity for febrile illness, and varied presentations of illness make diagnosis more difficult than in able-bodied individuals. In response, Korupolu et al. [2] do an excellent job summarizing the potential impacts of COVID-19 on persons with SCIs and the special care that must be taken in triaging that is important to read.

At present, we should all use this knowledge optimally and bring necessary information to professionals who work in general medicine and acute care. We must also share with our physician and allied health colleagues who work in the field of SCI and with persons who live with SCIs, their family members, and caregivers. As SCI has been likened to a bellweather [3] and there are many similarities in morbidities between persons with SCI and those experienced in relation to other disabilities, let us share this useful information with our colleagues working in the general field of 
rehabilitation and people and families who experience the impact of disability on their daily lives. Finally, let us learn from the present as we move into the future. This will be time well spent, provided we utilize new knowledge obtained during the COVID-19 crisis to inform future practice and lifestyle changes.

\section{Compliance with ethical standards}

Conflict of interest The author is the CEO of the nonprofit organization, Telerehabilitation International Co., and the Executive Producer of the YouTube Channel, Sustain Our Abilities. She declares no conflicts of interest in these volunteer roles.

Publisher's note Springer Nature remains neutral with regard to jurisdictional claims in published maps and institutional affiliations.

\section{References}

1. Shapiro LT, Gater DR, Shultz JM. It's time to put hurricane preparedness on the radar for individuals living with spinal cord injury.
Spinal Cord Ser Cases. 2020. https://doi.org/10.1038/s41394-0200282-9.

2. Korupolu R, Stampas A, Gibbons C, Hernandez Jimenez I, Skelton F, Verduzco-Gutierrez M. COVID-19: screening and triage challenges in people with disability due to spinal cord injury. Spinal Cord Ser Cases. 2020. https://doi.org/10.1038/s41394-020-0284-7.

3. Alexander M, Alexander J, Arora M, Slocum S, Middleton J. A bellweather for climate change and disability: educational needs of rehabilitation professionals regarding disaster management and spinal cord injuries. Spinal Cord Ser Cases. 2019;5. https://doi.org/ 10.1038/s41394-019-0239-z.

4. O'Connell CM, Eriks-Hoogland I, Middleton JW. Now, more than ever, our community is needed: spinal cord injury care during a global pandemic. Spinal Cord Ser Cases. 2020;6. https://doi.org/10. 1038/s41394-020-0270-0.

5. Alexander M. Let's conquer COVID-19 and sustain our abilities. Spinal Cord Ser Cases. 2020;6. https://doi.org/10.1038/s41394020-0271-z.

6. Stillman M, Capron M, Alexander M, Longoni M, Scivoletto G. COVID-19 and spinal cord injury and disease: results of an international survey. Spinal Cord Ser Cases. 2020;6:21. https://doi.org/ 10.1038/s41394-020-0275-8.

7. Righi G, Del Popolo G. COVID-19 tsunami: the first case of a spinal cord injury patient in Italy. Spinal Cord Ser Cases. 2020;6. https://doi.org/10.1038/s41394-020-0274-9. 